\title{
Plan formation, retention, and execution in prospective memory: A new approach and age-related effects
}

\author{
MATTHIAS KLIEGEL \\ University of Heidelberg, Heidelberg, Germany \\ MARK A. MCDANIEL \\ University of New Mexico, Albuquerque, New Mexico \\ and \\ GILLES O. EINSTEIN \\ Furman University, Greenville, South Carolina
}

\begin{abstract}
Existing laboratory paradigms of prospective memory instruct subjects to remember to perform a single, isolated act at an appropriate point in the experiment. These paradigms do not completely capture many everyday complex prospective memory situations in which a series or set of delayed actions is planned to be executed in some subsequent period of time. We adapted a laboratory paradigm within which to study these prospective memory processes, and we investigated age-related influences on these prospective memory processes. Age-related declines were found in the planning, initiation, and execution of the set of tasks. In contrast, there were no age differences in plan retention or in the fidelity with which the plan was performed.
\end{abstract}

Memory for activities to be performed in the future, such as remembering to take medication or remembering to give a colleague a message, is a pervasive real-world memory task that has recently begun to attract the attention of numerous researchers (see, e.g., Brandimonte, Einstein, \& McDaniel, 1996). (In keeping with the literature, we will term this type of memory prospective memory.) In the laboratory paradigms that have been developed to investigate prospective memory, subjects typically are busily involved in performing a cover activity and must remember on their own to perform a previously instructed prospective memory task, either once or several times (e.g., to press a designated key on a computer keyboard). In these types of experiments, the focus is on the processes and factors, including aging, that influence how subjects remember to perform a single, isolated act at the appropriate point during the experimental session (Einstein \& McDaniel, 1990; Einstein, McDaniel, Richardson, Guynn, \& Cunfer, 1995; Einstein, Smith, McDaniel, \& Shaw, 1997; Guynn, McDaniel, \& Einstein, 1998; Marsh \& Hicks, 1998; Maylor, 1996; McDaniel \& Einstein, 1993;

\footnotetext{
M.K.'s participation on this project was funded in part by a grant from Cusanuswerk (Bonn, Germany). Preparation of this article was supported in part by NASA Grant NCC-2-1085 to G.E. and M.M. We thank the volunteers from the New Mexico Aging Process Study (funded by National Institute on Aging Grant AG02049) for their participation. Correspondence concerning this article should be addressed to $\mathrm{M}$. A. McDaniel, Department of Psychology, University of New Mexico, Albuquerque, NM 87131-1161 (e-mail: mcdaniel@unm.edu).
}

McDaniel, Robinson-Riegler, \& Einstein, 1998; Park, Hertzog, Kidder, Morell, \& Mayhorn, 1997).

Though these simple paradigms have been fruitful in increasing our understanding of prospective memory, the extant studies do not completely capture more complex prospective memory situations in which several delayed actions are planned to be executed in some subsequent period of time. These more complex situations are likely to include planning processes like those used in forming a daily plan for a day's activities (Ellis, 1996), cooking a three-course meal (Byrne, 1977), or the planning that airtraffic controllers might engage in when they anticipate heavy traffic (Dougherty, Gronlund, Canning, Durso, \& Mills, 1998). In contrast, simple prospective memory tasks used thus far in the laboratory do not appear to involve much planning. For instance, Bisiacchi (1996) found no correlation between a planning measure and performance on simple prospective memory tasks. Consistent with these ideas, theoretical views propose that prospective remembering in these simple tasks is often relatively spontaneous and automatic (Guynn et al., 1998; McDaniel, RobinsonRiegler, \& Einstein, 1998).

There are five published studies of which we are aware that have used a task that bears some similarity to complex prospective memory. In four of the studies, the subjects had to perform a multiintention task; however, in these studies, the experimenter signaled the subject when it was time for each distinct action to be initiated (Kvavilashvili \& Chitashvili, 1991; Somerville, Wellmann, \& Cultice, 1983; West, 1988; Wilson, Cockburn, \& Baddeley, 1985). 
This paradigm appears to obviate the need for subjects to engage in active planning because the sequence and periods for performing each different task were completely constrained by the experimenter. In another study with several neuropsychological patients, the subjects were given six tasks (elements) to perform in a specified amount of time (but not all items of each element could be completed in the time period), and they were given some sequence constraints, such that the sequencing of the elements and the amount of time spent on each element required planning (Shallice \& Burgess, 1991). This six-element task is considered to reflect active planning processes. Because this task was immediately performed after instruction, however, planning, plan initiation, and plan execution processes could not be distinguished. Furthermore, the case study approach did not allow for investigation of individual differences in basic cognitive processes that might contribute to performance.

Thus, current findings and theories of prospective memory generally do not reflect the potential complexity of processes that may be involved in many everyday prospective memory activities, which include developing a plan, remembering the plan, and remembering at some future point to execute the plan. The objective of the present paper was to develop a laboratory paradigm that isolates each of these processes so that they can be more directly examined and to present experimental investigation of these components with aging as an initial focus.

The prospective memory task used in this experiment was a modification of the six-elements task developed by Shallice and Burgess (1991). In this task, the subjects were required to work within constraints on six subtasks in order to maximize their point totals. In order to add a prospective memory component to this task, the subjects were required to initiate the six-elements task on their own at some specified point in the experiment. Another major modification was that the subjects were required to explicitly generate a plan for completing the six-elements task. This allowed us to disentangle the planning stage from the execution stage. In other studies experimental procedures have blurred those processes (e.g., Shallice \& Burgess, 1991), and thus it has been difficult to specify whether the variables of interest affect planning per se, plan execution, or both. We also assessed plan retention. The subjects were required to recall their plan in the interval between the prospective memory instruction and the point at which they were to initiate the six-elements task. In sum, our version of the six-elements task consisted of several parts: introduction and planning for the sixelements tasks, plan recall after a first delay, and initiation and execution of the six-elements task after another delay (initial work in which planning in the six-elements task was investigated was reported by Burgess, 1996).

One variable that has been studied somewhat extensively in the prospective memory literature is age. A surprising pattern that has been found is that, in simple prospective memory tasks (e.g., pressing a key on the keyboard when a particular target word appears in the ongoing activity), age often does not produce significant differences in the initiation of the prospective memory activity (Cherry \& LeCompte, 1999; Einstein, Holland, McDaniel, \& Guynn, 1992; Einstein \& McDaniel, 1990; Einstein et al., 1995; Einstein et al., 1997; although see Maylor, 1996, and Park et al., 1997, for a different finding). From this previous research, however, it is not clear whether one would expect to find age differences in planning processes associated with prospective memory. In the problem-solving literature, for chess problems that involve planning ahead, older adults who are chess experts solved these problems as well as younger experts, even though the the older adults did not engage in as extensive search of the possible moves (Charness, 1981). Assuming that older adults are very experienced in complex, everyday prospective memory tasks, one might anticipate that plan formation in prospective memory would not be compromised by aging. On the other hand, some past research has shown that there are age-related declines in planning (Lachman \& Burack, 1993; Martin $\&$ Ewert, 1997), and, thus, there may be age-related differences in planning in the present task.

The expected age pattern for plan retention appears to be more straightforward. In light of the extensively documented age differences in recall (see Light, 1991, for a review), we would expect older adults to have more difficulty recollecting their plans. For a similar reason, and because of the demands of concurrently recalling and executing plan components, older adults would be expected to show deficits in plan execution.

Another important component is the ability to remember to initiate the planned actions. As noted earlier, past research is equivocal on whether to expect age differences in this component. One framework suggests that, if strategic monitoring of the target or enabling event is involved in the task, age differences would be obtained; if subjects rely on more automatic retrieval processes for remembering to initiate the action, no age differences would be expected (McDaniel, 1995; McDaniel, Einstein, Manzi, \& Cochran, 1998). In the present paradigm, the degree to which the subjects are likely to rely on strategic monitoring is unclear a priori. If it were the case, however, that there were independent indications that strategic monitoring were occurring, age declines in initiation should emerge. Specifically, to the extent that strategic monitoring involves executive or working-memory capacity and inhibition, initiation could be considered a marker of strategic monitoring.

More generally, to the degree that age-sensitive processes like working memory, inhibition, and retrospective memory are important in the planning processes of interest here, one might expect the age-related differences to be especially pronounced. Indeed, these fundamental cognitive processes might underlie any observed age differences. We directly tested these latter ideas by including tasks that would enable us to assess individual differences on these cognitive processes. These individual-differences tasks also were useful in keeping the subjects busily en- 
gaged so that they did not continuously maintain the prospective memory task in working memory throughout the experiment (thereby enabling examination of a long-term prospective memory task).

\section{METHOD}

\section{Subjects}

The 62 subjects in this study, including 31 younger and 31 older adults, were tested by one experimenter. The subjects completed the entire procedure in an average time of $70 \mathrm{~min}$. The younger adults were undergraduate students in a psychology course at the University of New Mexico. They received extra credit for their participation. The older subjects were community dwelling adults involved in a large ongoing aging processes study conducted at the University of New Mexico Medical School. They volunteered for the present experiment in response to a mail solicitation. As Table 1 indicates, the groups were comparable in terms of sex, education, and self-reported health.

\section{Procedure}

The procedure consisted of three phases: (1) an introduction phase in which the subjects were instructed on the prospective memory task and were required to develop a plan; (2) a delay phase in which the individual-difference variables (i.e., working memory, retrospective memory, and inhibition) were assessed and memory for the plan was tested; and (3) a performance phase in which the prospective memory task was to be initiated and executed.

The introduction phase. At the beginning of the experiment, after the general introduction and informed consent, the subjects were given instructions for one of the prospective memory tasks in the Rivermead Behavioral Memory Test (Wilson et al., 1985). The task was to remind the experimenter, at the end of the entire experiment, to return a personal belonging (most often a wristwatch was the selected personal belonging), which had been taken from the subject at the beginning of the experiment. Then the subjects were told that at a certain point they would have to fill out a personal information questionnaire (as noted below, this was the cue for initiating the complex prospective memory task, i.e., the modified sixelements task). The subjects were informed that this task would take place during the second part of the experiment, after a short break and some other tasks.

Using example sheets, the tasks and the rules of our modified sixelements task were explained to the subjects. Specifically, the subjects were asked to carry out six subtasks in a 6-min time period (instead of the 15-min period used by Shallice $\&$ Burgess, 1991) in a way that would maximize their overall scores. The six subtasks were divided into two similar sets (sets A and B) of three (word finding, solving arithmetic problems, and writing down the names of pictures). We designed each subtask so that it would take more than $1 \mathrm{~min}$ to complete. The two sets of word finding problems (based

Table 1

Demographic Characteristics of Younger and Older Adults

\begin{tabular}{|c|c|c|c|c|}
\hline \multirow[b]{2}{*}{ Measure } & \multicolumn{2}{|c|}{$\begin{array}{c}\text { Younger Adults } \\
(N=31)\end{array}$} & \multicolumn{2}{|c|}{$\begin{array}{l}\text { Older Adult } \\
(N=31)\end{array}$} \\
\hline & $M$ & $S D$ & $M$ & $S D$ \\
\hline Age (years) & 26.5 & 5.8 & 71.3 & 6.2 \\
\hline Education (years) & 15.6 & 1.1 & 15.0 & 2.3 \\
\hline $\begin{array}{l}\text { Subjective health status } \\
\text { (5-point scale) }\end{array}$ & 4.13 & .85 & 3.97 & .75 \\
\hline
\end{tabular}

Note-Age range for younger adults, $20-48$ years; for older adults, 62-83 years. Of younger adults, 8 were males, 23 females; of older adults, 10 were males, 21 females. Subjective health status was measured on a scale from 1 (poor) to 5 (excellent). on a German vocabulary test, MWT-B; Lehrl, 1977) consisted of 35 groups of 4 items. In each group there was one word and three similarly spelled or similarly sounding pseudowords (e.g., conceal, concill, cauncil, concel). The subject's task was to circle the actual words. Each set of arithmetic problems contained 10 problems (e.g., $300 / 6 \times 4=$ ); both sets were equivalent in difficulty. Finally, the 20 pictures in each set were pictures of common objects or symbols (e.g., a house). Here, the subject's task was to name the pictures with an appropriate label. The subjects were told that there was no perfect answer in this subtask and that they should write down whatever they thought was the best label for the pictures.

After explaining the subtasks, the subjects were told where the material for these subtasks was stored (in the second drawer of the subject's table, divided into three file folders, according to the task type) and that there would be a few rules to follow. Using a rule sheet, the rules were shown and explained to the subject. The rules were as follows:

1. Your aim is to maximize your score. (A) Earlier pictures/problem/word groups will be given more points than later ones in each subtask. (b) Points will be given for correct answers, and performance errors or omissions will be penalized. (c) Each of the six subtasks will be given equal weight.

2. You are not allowed to do two sub-tasks (A) and (B) of the same type one after the other.

3. You will have 6 minutes.

4. Please press the start-button of this stopwatch to start the timing of the tasks yourself.

The subjects were tested on the recall of these rules, and any errors or omissions were corrected. Once they were aware of the rules, the subjects were told that, in addition, they would have to open the drawer and start these tasks by themselves after answering the question about their date of birth in the personal information questionnaire that had been previously explained to them.

Finally, the subjects were asked to develop a plan for the prospective memory task. The planning had to be verbal and was recorded on a cassette tape.

The delay phase. The working memory test was presented next. This test was taken from Waters and Caplan (1996). In this task, the subjects were presented with a series of sentences on the video screen of a computer. They were asked to make judgments about the acceptability of each sentence in the series and to remember the last word of each sentence in a series. All sentences were of the same syntactic structure (i.e., self-embedded; e.g., The meat that the butcher cut delighted the customer). Half of the sentences were acceptable, whereas the other half was not. Unacceptable sentences were formed by inverting the animacy of the subject and object noun phrase (e.g., The fire that the child harmed burned down the building). The sentences were all 8 to 11 words in length.

On each trial, an asterisk appeared on the computer screen, followed $200 \mathrm{msec}$ later by the first sentence in the series. The subject had to read the sentence silently and then push, as fast as possible, the yes response key if the sentence was acceptable or the no response key if the sentence was unacceptable. As soon as a decision about one sentence had been made, the next sentence in the series was presented. After the last sentence was processed, an asterisk appeared that prompted the serial recall of the last word of each of the sentences in the series. The subjects had to write their responses on an answer sheet. They were instructed to perform the sentence task very accurately, and then to perform as well as they could on the recall task.

Four sets of two sentences each were presented for practice, followed by 100 target sentences. The 100 sentences were divided into five sets of sentences at each of the span sizes $2,3,4,5$, and 6 . The testing began with a series of two sentences (span size 2 ) and continued through span size 6 for all subjects. According to Waters and Caplan (1996), by computing a composite score that includes lastword recall, reaction time, and performance in the sentence rating, 
one gains a more valid and reliable estimate of working memory functioning. The particular version of their task that we implemented has a test-retest reliability of .83 (Waters \& Caplan, 1996).

After completing the working memory test, the subjects had to recall their plans for the complex prospective memory task. Recall occurred about $25 \mathrm{~min}$ after the plan had been constructed. Next, the digit-symbol subtask of the Wechsler Adult Intelligence Scale was administered as a distractor task (revised version; Wechsler, 1981).

After a short break ( $5 \mathrm{~min}$ ), retrospective memory ability was assessed. The study material for the retrospective memory test was action phrases (to drive a car; cf. Cohen, 1981; Engelkamp, 1991). Martin and Schumann-Hengsteler (1996) have suggested that this type of material better equates the contents of retrospective and prospective memory tasks. There were 16 actions to learn, and each action was presented on a card for $5 \mathrm{sec}$. The delay between study and test was approximately $4 \mathrm{~min}$. At test, the subjects had $2 \mathrm{~min}$ to free recall the action phrases. The delay was filled with the colorword Stroop test, described next.

We included a traditional color-word version of the Stroop task (cf. Stroop, 1935; for applications cf. Cohn, Dustman, \& Bradford, 1984; Houx, Jolles, \& Vreeling, 1993) in order to measure inhibition (e.g., Dempster, 1992; Salthouse \& Meinz, 1995; Spieler, Balota, \& Faust, 1996). In this task, the word stimuli consisted of four color names (red, blue, green, and yellow) written in black ink (Trial 1 consisted of reading the words as fast as possible), the four color names printed in color bars (Trial 2 consisted of naming the colors as fast as possible), and the four color names printed in mismatching colors (Trial 3 consisted of naming the colors of the words as fast as possible). Each Stroop condition began with practice of the top line consisting of 5 items followed by timed performance on the 20 test items (consisting of five rows of 4 items each).

The performance phase. After action-phrase recall, the subjects were given the personal-information questionnaire. After having answered the question about their dates of birth, the subjects were supposed to initiate the prospective memory task by themselves. If they did not start after having finished the entire questionnaire, the experimenter prompted them to do so and asked whether they could recall when they were supposed to have started the six tasks. After having worked on the six-elements task for $6 \mathrm{~min}$, the subjects filled out the rest of the personal-information questionnaire and were debriefed by the experimenter. At this time, it was noted whether or not the subjects asked for their personal belonging. If a subject left the room without asking for it, the experimenter gave it back to $\mathrm{him} / \mathrm{her}$ and noted a failure in single-task prospective memory.

\section{RESULTS}

Unless otherwise indicated, the rejection level for inferring statistical significance was set at .05 . We first performed analyses of variance (ANOVAs) in order to compare the younger and older adults on the various components of the complex prospective memory task and on the single-task prospective memory task. We then applied multiple regression analyses in order to reveal the underlying cognitive processes associated with complex prospective memory performance and to indicate the extent to which these processes reflected the obtained age-related effects. The regression analyses were also designed to investigate the degree to which plan elaboration and retention were associated with execution of the prospective memory task.

\section{Complex Prospective Memory}

The elaborateness of the plan was analyzed in terms of a score that included three main features: (1) the number of rules included in the subject's plan (e.g., Since I'm not allowed to do two tasks of the same type in sequence), (2) the number of times the subject specified a particular order for performing a task by giving a reason for this step (e.g., I will do the pictures first, because I think I can do them more quickly), and (3) the number of executable items of the plan. In order to assess the number of executable items, we noted how many executable steps the subject indicated; that is, the number of task steps he/she planned to initiate (words, pictures, and/or arithmetic problems were given 1 point each) and whether the subject specified the steps concerning the version (A or B was scored 1 point each), the time he/she planned to spend on each step, or the number of items he/she planned to complete in each step (which were given 1 point each). The plan-elaboration score was the sum of the number of features (described above) included in the plan. The theoretical minimum score was 0 , which would indicate that the subject did not plan at all. The minimum score for the simplest but correct and complete plan was 7 (e.g., recorded plan: First, I will do all versions $A$ and then all versions $B$ would yield a score of 7 [6 executable items: A, A, A, B, B, and B, and one rule included implicitlyRule 2, not performing two subtasks of the same task successively]). The maximum score is in principle unlimited. The scoring was done by two independent raters, and the degree of agreement was high $[r(62)=.95]$. A concrete example of a scored protocol is provided in the Appendix.

The range for the scores was from 7 to 40 for the younger adults and 7 to 38 for the older adults. A onefactor ANOVA revealed that the younger adults had significantly more elaborate plans than did the older adults $(M=17.42, S D=8.21$ vs. $M=12.61, S D=5.85)$ $\left[F(1,60)=7.04, M S_{\mathrm{e}}=50.85\right]$. This difference was mostly due to the fact that many of the older subjects simply planned first to do all versions $A$ and then all versions $B$ in order to avoid a Rule 2 error. The older subjects tended to not produce many thoughts about their own preferences nor did they generate cues to signal when to interrupt an ongoing subtask in order to initiate another one. These types of elements were more prevalent in the younger adults' plans.

Plan retention was measured in terms of the fidelity of what was recalled relative to the previously stated plan. No age effects were found for plan retention. Both groups recalled almost all elements of their plans (younger adults: $M=93.6 \%, S D=15.28$; older adults: $M=$ $91.9 \%, S D=17.14)$.

Plan initiation was assessed by whether the subjects initiated the tasks after they had written their dates of birth on the personal information form. Overall, $50 \%$ of the subjects forgot to initiate performance of the six tasks at the appropriate moment (i.e., after having filled in their dates of birth on the personal information questionnaire). This was the case despite the fact that when they were prompted by the experimenter to do so at the end of the personal information questionnaire, every subject was able to recall the event (i.e., fill in date of birth), signal- 
ing initiation of the six-elements prospective memory task. An analysis of initiation as a function of age (forgetting was scored with a " 0 " and remembering was scored with a " 1 ") showed that the younger adults were more likely to initiate the prospective memory task $(64.5 \%)$ than were the older adults $(35.5 \%)[F(1,60)=$ $\left.5.52, M S_{\mathrm{e}}=.24\right]$.

Our measure of prospective memory execution was the number of subtasks that were started (out of six possible tasks). Overall, the subjects executed an average of 3.68 subtasks $(S D=.97)$. A single-factor ANOVA revealed that the younger adults $(M=4.06, S D=.77)$ executed more tasks than did the older adults $(M=3.29$, $S D=1.0)\left[F(1,60)=11.51, M S_{\mathrm{e}}=.80\right]$.

Finally, plan fidelity was assessed by comparing the actual executed items with the executable items of the subject's original plan. The analysis showed no age differences; both groups executed a similar proportion of items stated in their original plans (younger adults: $M=50.0 \%$, $S D=22.19$; older adults: $M=47.0 \%, S D=22.13 ; F<$ 1). It is interesting, however, that compared with the high overall plan retention $(M=92.8 \%, S D=16.13$; see above), the subjects executed their plans with an average fidelity of only $48.5 \%(S D=22.03)$, and only 1 subject executed the plan with $100 \%$ fidelity. The large difference between recalled items and actual executed items was significant $[t(61)=15.38]$.

\section{Single-Task Prospective Memory}

Overall, $54.1 \%$ of the subjects remembered to ask the experimenter for their personal belongings at the end of the experiment. An analysis of these results (forgetting was scored 0 ; remembering was scored 1 ) revealed no significant age effects $(48.4 \%$ and $60.0 \%$ remembering in the younger and older groups, respectively; $F<1$ ).

\section{Individual Differences Analyses of Prospective Memory}

Single-factor ANOVAs were initially performed to determine whether there were reliable differences between the younger and older adults on the individual difference measures of working memory, inhibition, and retrospective memory.

In order to analyze the working memory measure, we followed Waters and Caplan's (1996) procedure for computing (1) the mean reaction time for processing the sentences for correct responses, (2) the number of errors on the sentences, and (3) the number of trials in which the subjects did not correctly recall the words. Thus, for each of these components of the Waters-Caplan task, lower scores represent better performance. Each subject's score on each component was converted to a $z$ score. The $z$ scores for each subject were averaged to create a composite $z$ score. The composite $z$ score provided an overall working memory score that assigns equal weighting to the speed of processing the sentences, the accuracy of processing the sentences, and the accuracy of recall.
The mean composite score (expressed as a $z$ score) was significantly lower (representing higher performance) in the younger adults $(M=-.19, S D=.52)$ than in the older adults $(M=.19, S D=.55)\left[F(1,60)=7.57, M S_{\mathrm{e}}=.29\right]$.

Free recall on the retrospective memory task was scored by the number of actions correctly recalled. The younger adults $(M=5.84, S D=2.45)$ recalled significantly more actions than did the older adults $(M=4.39, S D=1.96)$ $\left[F(1,60)=6.63, M S_{\mathrm{e}}=4.93\right]$. Our measure of inhibition on the Stroop task was patterned after typical approaches; that is, the increase in time to name the color of the ink of the color words relative to the time to name the color of the color blocks was divided by the baseline of word naming (in order to account for general speed differences across groups; Spieler et al., 1996). Larger relative increases in time to name the color of the ink of the color words indicate less inhibition. The older adults $(M=2.52$, $S D=.98$ ) showed significant decrements in inhibition relative to inhibition in the younger adults $(M=.77, S D=$ .43) $\left[F(1,60)=83.15, M S_{\mathrm{e}}=.57\right]$.

We adopted the following approach in conducting the multiple regression analyses. For all prospective memory measures, we first included the working memory, inhibition, and retrospective memory measures as predictors. Also, we included all of the prospective memory assessments that preceded the prospective memory component of interest (e.g., plan elaboration and plan retention were included as predictors for plan initiation). Next, for each prospective memory component for which the ANOVAs revealed age effects, we entered age in a second regression as an additional predictor. Of interest here was whether age remained a significant factor when basic cognitive processes were simultaneously considered. If age were no longer significantly associated with prospective memory, the implication would be that the age effect may be related to declines in the cognitive processes assessed by the individual difference measures (cf. Salthouse, 1994).

For plan elaboration there were no significant predictors, except for age (paralleling the ANOVA). There were also no significant predictors for plan retention. For plan initiation, working memory was significantly associated with performance such that as capacity increased, so too did the likelihood of initiating the prospective memory task (see Table 2 for the regression summary). Inhibition was also significantly related to initiation, with declines in inhibition producing less successful initiation. Age

Table 2

Summary of Regression Analysis for Predicting Initiation of the Complex Prospective Memory Task

\begin{tabular}{lcccc}
\multicolumn{1}{c}{ Variable } & $B$ & $S E B$ & $\beta$ & \multicolumn{1}{c}{$t$} \\
\hline Inhibition & -.15 & .05 & -.34 & $-2.76^{*}$ \\
Working memory & -.27 & .11 & -.30 & $-2.46^{*}$ \\
Retrospective memory & .03 & .03 & .12 & .97 \\
Plan elaboration & -.01 & .01 & -.14 & -1.19 \\
Plan retention & .003 & .003 & .11 & .97 \\
$\quad$ Total $R^{2}=.35$ & & & & \\
\hline
\end{tabular}

${ }^{*} p<.05$. 
was no longer significantly associated with plan initiation once the influences of working memory and inhibition were taken into account $(p<.85$ for the beta's being significantly different from zero).

For the execution component, we conducted regression analyses on two dependent measures - the fidelity of execution of the plan and the number of subtasks initiated. As can be seen in Table 3, plan elaboration, plan retention, and working memory capacity all accounted for a significant proportion of variance in the extent to which execution matched the initial plan. Fidelity increased as plan elaboration decreased, as the plan was better remembered, and as working memory capacity increased.

The regression for the number of subtasks executed revealed that plan elaboration was positively associated with the number of subtasks executed. Also, the more closely the plan was followed, the more subtasks that were executed. Finally, greater inhibitory capabilities were associated with an increase in subtasks executed (see Table 4). After taking these factors into account, age was not significantly associated with task execution $(p<.81$ for the beta's being different from zero).

There were no significant predictors from the individual difference measures for the single-task prospective memory performance.

\section{DISCUSSION}

In this study, we developed a new paradigm that seems to capture many aspects of real-world prospective memory tasks that have not been reflected in previous laboratory paradigms. Our paradigm requires subjects to engage in a range of processes that include making a plan, retaining the intended plan, and executing a series of multiple intentions (tasks). Such processes appear in self-reports of naturalistic prospective memory activities (Marsh, Hicks, \& Landau, 1998) and are included in many theoretical accounts of prospective memory (Burgess \& Shallice, 1997; Dobbs \& Reeves, 1996; Ellis, 1996). However, existing laboratory paradigms that require subjects to remember to perform one simple activity at a specified point in an experiment, likely obviate the need for planning and scheduling of several competing actions. Thus, these paradigms may not generally afford the opportunity to examine the range of cognitive activities in-

Table 3

Summary of Regression Analysis for Predicting

Fidelity of Execution With Original Plan

\begin{tabular}{lrrrr}
\hline \multicolumn{1}{c}{ Variable } & \multicolumn{1}{c}{$B$} & $S E B$ & \multicolumn{1}{c}{$\beta$} & \multicolumn{1}{c}{$t$} \\
\hline Working memory & -10.37 & 4.65 & -.27 & $-2.23^{*}$ \\
Plan elaboration & -1.07 & .33 & -.36 & $-3.19^{*}$ \\
Plan retention & .46 & .15 & .34 & $3.07^{*}$ \\
Inhibition & -2.98 & 2.31 & -.16 & -1.29 \\
Retrospective memory & .70 & 1.13 & .07 & .62 \\
$\quad$ & & & & \\
$\quad$ Total $R^{2}=.36$ & & & & \\
${ }^{*} p<.05$. & & & &
\end{tabular}

Table 4

Summary of Regression Analysis for Predicting Number of Subtasks Executed

\begin{tabular}{lrrrr}
\hline \multicolumn{1}{c}{ Variable } & \multicolumn{1}{c}{$B$} & $S E B$ & \multicolumn{1}{c}{$\beta$} & \multicolumn{1}{c}{$t$} \\
\hline Inhibition & -.20 & .10 & -.24 & $-2.00^{*}$ \\
Plan elaboration & .05 & .02 & .36 & $3.00 \dagger$ \\
Fidelity with plan & .02 & .01 & .38 & $2.93 \dagger$ \\
Working memory & -.30 & .21 & -.18 & -1.48 \\
Retrospective memory & .02 & .05 & .05 & .44 \\
Plan retention & -.01 & .01 & -.09 & -.83 \\
$\quad$ Total $R^{2}=.42$ & & & & \\
\hline
\end{tabular}

${ }^{*} p=.05 . \quad{ }^{\dagger} p<.05$.

volved in more complex real-world prospective memory tasks. In addition, this is the first published study of which we are aware that explicitly disentangles prospective memory planning from plan execution. Several interesting and somewhat novel findings emerged.

First, we found evidence that planning and executing of prospective memory tasks have, in fact, to be distinguished: The formulated plan did not overlap substantially with the manner in which the prospective memory tasks were executed. This finding is in line with naturalistic survey work showing that the execution (or the absence thereof) of prospective memory tasks not infrequently diverges from the originally planned intentions (Marsh et al., 1998). Marsh et al. noted that this divergence was due to reprioritizing intentions and to unanticipated demands, factors that could have been operative as well in the present study. However, our findings also pinpoint other factors that are associated with the fidelity with which plans are executed. Reasonably, execution was more faithful for better-retained plans. Also, individuals with greater working memory and less elaborate plans were more likely to execute their plans as originally formulated. This pattern may imply that good execution of a plan, at least for a set of more complex actions, requires that the plan be reinstated into working memory at points during execution in order to guide and monitor execution of the task. Such a process would presumably be facilitated when plans are more succinct and easier to remember, as well as for individuals with greater working memory capability.

The present findings on aging and prospective memory underscore the utility of experimentally revealing the various components thought to be involved in more complex prospective memory tasks (see Dobbs \& Reeves, 1996; Ellis, 1996). On the average, the older adults formed less elaborate plans than did the younger adults; the older adults were significantly less likely to remember to initiate the intended actions than were the younger adults, and the older adults performed more poorly in executing the intended actions than did the younger adults. In contrast, the older adults retained the plan that they constructed as well as the younger adults did and executed that plan with as much fidelity as the younger adults did. Thus, our initial independent variable of interest (age) did not 
impact all components of prospective memory equally. A more refined analyses of these components reveals additional insights, as discussed below.

The obtained age-related impairments were anticipated in light of the theoretical assumption that complex prospective memory requires relatively active, strategic processes. Such strategic processes would be expected to be supported by working memory capabilities and by inhibitory mechanisms. The regression analyses confirmed that both working memory and inhibition (as measured by Stroop performance) were associated with initiating the prospective memory task, and inhibition was significantly associated with the number of tasks executed (consistent with Shallice \& Burgess's, 1991, finding that patients with disinhibition showed deficits in completion of the six-elements task). Moreover, these capabilities were found to show age-related declines (converging with previous findings; e.g., Craik \& Jennings, 1992; Hasher, Stoltzfus, Zacks, \& Rypma, 1991; Park et al., 1997; Salthouse, 1991; Zacks \& Hasher, 1994). Thus, the age-related deterioration of basic cognitive processes like working memory and inhibition may be fundamental to the observed age-related declines in prospective memory (see also Cherry \& LeCompte, 1999). This possibility is supported by our finding that when these individual difference measures were used as predictors for prospective memory, age was no longer associated with either initiation or execution of the complex prospective memory task. It is also noteworthy that the elaborateness of a plan was related to successful execution, and that this predictor also was important in eliminating the age effects in execution. These patterns from the regression analyses provide general support for theoretical views (e.g., Dobbs \& Reeves, 1996; Ellis, 1996) that assume that prospective memory performance is not primarily reflective of a unitary memory process, but rather is supported by a collection of different activities (e.g., planning, content recall, monitoring, and output monitoring). Our results also extend these views to a more elemental level of analysis by demonstrating the influence of basic cognitive processes like working memory and inhibition on aspects of prospective memory performance.

An important finding with regard to the issue of aging and prospective memory was that the older adults were significantly less likely to remember to initiate the actions than were the younger adults. This pattern is contrary to our initial laboratory work that showed no age differences with prospective memory tasks in which a single action had to be performed when cued by a particular environmental event (Einstein \& McDaniel, 1990; Einstein et al., 1995, Experiments 1 and 3) and to the present finding of no age differences on the single-task prospective memory activity. One interpretation of this divergent pattern is that prospective memory tasks that do not heavily rely on working memory or inhibitory functioning may be relatively immune to age effects. In line with this interpretation, performance on the singletask prospective memory task used here was not associated with working memory or inhibition. Additionally, Cherry and LeCompte (1999) recently reported a nonsignificant age effect on a prospective memory task for which working memory had only a slight (though significant) association. Also consistent with this analysis, Park et al. (1997) reported age-related decrements in a single-task prospective memory paradigm, and prospective memory performance was associated with working memory processes in older adults.

Although the correlational data are in line with this interpretation, there remains the question of why initiation of the complex task but not the simple task would require working memory and inhibitory processes. The two tasks are seemingly equivalent on the following important dimension: In both cases, the subjects were given a specified retrieval occasion (cue) for when to perform an intended action, or actions. ${ }^{1}$ It may be that the experimental procedure requiring planning and plan recall of the complex but not the simple task may have served to emphasize the complex prospective memory task, thereby leading the subjects to deploy controlled processes (e.g., monitoring for the prospective-memory cue) to perform the task. The simple task, by contrast, was not associated with such procedures, and the subject's attention was continually distracted from this prospective memory task (by the ongoing tasks) after its initial mention (a procedure that parallels that used in our previous laboratory experiments with single-task prospective memory). Accordingly, prospective memory performance in the single task may have been supported by a more automatic memory retrieval process that does not demand processes like working memory and inhibition (cf. Einstein et al., 1997; Guynn, McDaniel, \& Einstein, in press; McDaniel, Robinson-Riegler, \& Einstein, 1998). In principle, though, it should be noted that different task demands could encourage either a strategic or an automatic retrieval process with either single or complex tasks.

The absence of significant age differences in the fidelity with which a plan was executed and in plan retention (which was quite high for both age groups) seems somewhat surprising at first blush. However, fidelity was associated with less elaborate plans, and the older adults tended to produce less elaborate plans. Thus, the planning behavior of the older adults was congruent with the determinants of fidelity of execution. The plan retention findings converge with Marsh et al.'s (1998) report that despite prevailing beliefs, retention of prospective memory plans in naturalistic settings is quite good. The absence of age differences in plan recall, however, does seem to be in contradiction to prior research on retrospective memory and aging (see Light, 1991; Smith \& Earles, 1996), as well as incompatible with the significant age-related deficits found in the retrospective recall task (recalling lists of action sequences). There are several plausible rea- 
sons for these differences. One is that the plans were selfgenerated, whereas the lists were not. Self-generation in some cases can reduce age-related declines in recall. Second, the plans were integrated, functional events, whereas the lists were arbitrary, unrelated items.

In closing, we reinforce the observation that complex prospective memory situations likely involve basic cognitive processes for which there is much current interest. In these situations, the person must hold multiple intentions in mind in the face of ongoing distraction, and our initial results confirmed a significant association between working memory skills and successfully remembering to initiate the previously encoded intentions. This association probably does not imply that the subjects kept the intended actions in mind throughout the delay. Rather, it is more likely that higher working memory capacity facilitated periodic "refreshing" or reminding of the intended actions throughout the delay (in a similar vein, Ellis \& Shallice, 1993, reported periodic reviewing of intended activities throughout the day). Inhibitory processes that are also of general interest in cognition, particularly with regard to age-related declines (e.g., Hasher \& Zacks, 1988; Martin \& Ewert, 1997), seem to be required in this type of complex prospective memory task in order to inhibit ongoing activity, to allow initiation of the intended plan and execution of the multiple tasks. Thus, complex prospective memory seems to be a fruitful cognitive task for studying the interplay between a number of basic cognitive functions like working memory, inhibition, and planning.

\section{REFERENCES}

BisiaCCHI, P. S. (1996). The neuropsychological approach in the study of prospective memory. In M. Brandimonte, G. O. Einstein, \& M. A. McDaniel (Eds.), Prospective memory: Theory and applications (pp. 297-318). Mahwah, NJ: Erlbaum.

Brandimonte, M., Einstein, G. O., \& McDaniel, M. A. (Eds.) (1996). Prospective memory: Theory and applications. Mahwah, NJ: Erlbaum.

BuRGESS, P. W. (1996, July). Prospective memory following frontal lobe damage. Paper presented at the Second International Conference on Memory, Abano-Padua, Italy.

Burgess, P. W., \& Shallice, T. (1997). The relationship between prospective and retrospective memory: Neuropsychological evidence. In M. A. Conway (Ed.), Cognitive models of memory (pp. 247-272) Cambridge, MA: MIT Press.

Byrne, R. (1977). Planning meals: Problem-solving on a real database. Cognition, 5, 287-332.

Charness, N. (1981). Search in chess: Age and skill differences. Journal of Experimental Psychology: Human Perception \& Performance, $7,467-476$

Cherry, K. E., \& LeCompte, D. C. (1999). Age and individual differences in prospective memory. Psychology \& Aging, 14, 60-76.

COHEN, R. L. (1981). On the generality of some memory laws. Scandinavian Journal of Psychology, 85, 273-282.

Conn, N. B., Dustman, R. E., \& Bradford, D. C. (1984). Age-related decrements in Stroop color test performance. Journal of Clinical Psychology, 40, 1244-1250.

Craik, F. I. M., \& Jennings, J. M. (1992). Human memory. In F. I. M. Craik \& T. A. Salthouse (Eds.), The handbook of aging and cognition (pp. 51-110). Hillsdale, NJ: Erlbaum.

DEMPSTER. F. N. (1992). The rise and fall of the inhibitory mechanism: Toward a unified theory of cognitive development and aging. Developmental Review, 12, 45-75.
Dobss, A. R., \& Reeves, M. B. (1996). Prospective memory: More than memory. In M. Brandimonte, G. O. Einstein, \& M. A. McDaniel (Eds.), Prospective memory: Theory and applications (pp. 199-225). Mahwah, NJ: Erlbaum.

Dougherty, M. R. P., Gronlund, S. D., Canning, J. M.. Durso, F. T., \& Mills, S. H. (1998, May). Plan generation in air-traffic control. Paper presented at the Tenth International Symposium on Aviation Psychology, Columbus, $\mathrm{OH}$.

Einstein, G. O., Holland, L. J., McDaniel, M. A., \& Guynn, M. J. (1992). Age-related deficits in prospective memory: The influence of task complexity. Psychology \& Aging, 7, 471-478.

Einstein, G. O., \& MCDaniel, M. A. (1990). Normal aging and prospective memory. Journal of Experimental Psychology: Learning. Memory, \& Cognition, 16, 717-726.

Einstein, G. O., McDaniel, M. A., Richardson, S. L., Guynn, M. J., \& CUNFER, A. R. (1995). Aging and prospective memory: Examining the influences of self-initiated retrieval processes. Journal of Experimental Psychology: Learning, Memory, \& Cognition, 21, 996-1007.

Einstein, G. O., Smith, R. E., McDaniel, M. A., \& Shaw, P. (1997). Aging and prospective memory: The influence of increased task demands at encoding and retrieval. Psychology \& Aging, 12, 479-488.

ELLIS, J. A. (1996). Prospective memory or the realization of delayed intentions: A conceptual framework for research. In M. Brandimonte, G. O. Einstein, \& M. A. McDaniel (Eds.), Prospective memory: Theory and applications (pp. 1-22). Mahwah, NJ: Erlbaum.

Ellis, J. A., \& ShAlliCE, T. (1993). Memory for, and the organization of, future intentions. Manuscript submitted for publication.

ENGELKAMP, J. (1991). Memory of action events: Some implications for memory theory and for imagery. In C. Cornoldi \& M. A. McDaniel (Eds.), Imagery \& cognition (pp. 183-219). New York: Springer-Verlag. Guynn, M. J., McDaniel, M. A., \& Einstein, G. O. (1998). Prospective memory: When reminders fail. Memory \& Cognition, 26, 287-298.

Guynn, M. J., McDaniel, M. A., \& Einstein, G. O. (in press). Remembering to perform actions: A different type of memory? In H. D. Zimmer \& R. L. Cohen (Eds.), Memory for action: A distinct form of episodic memory? New York: Oxford University Press.

Hasher, L., Stoltzfus, E. R., Zacks, R. T., \& Rypma, B. (1991). Age and inhibition. Journal of Experimental Psychology: Learning, Memory, \& Cognition, 17, 163-169.

HASHER, L., \& ZACKS, R. T. (1988). Working memory, comprehension, and aging: A review and a new view. In G. H. Bower (Ed.), The psychology of learning and motivation (Vol. 22, pp. 193-225). San Diego: Academic Press.

Houx, P. J., Jolles, J., \& VReeling, F. W. (1993). Stroop interference: Aging effects assessed with the Stroop color-word test. Experimental Aging Research, 19, 209-224.

Kvavilashvili, L., \& Chitashvili, M. (1991). Forgetting intentions as a stable personality characteristic and the problem of its quantitative measurement. Matsne: Series in Philosophy \& Psychology, 3, 67-78 [in Georgian].

Lachman, M. E., \& Burack, O. R. (1993). Planning and control processes across the life span: An overview. International Journal of Behavioral Development, 16, 131-143.

LEHRL, S. (1977). Der Mehrfachwahlwortschatztest MWT-B. Erlangen: Straube.

LIGHT, L. L. (1991). Memory and aging: Four hypotheses in search of data. Annual Review of Psychology, 42, 333-376.

MARSH, R. L., \& Hicks, J. L. (1998). Event-based prospective memory and executive control of working memory. Journal of Experimental Psychology: Learning, Memory, \& Cognition, 24, 336-349.

MARSH, R. L., HICKS, J. L., \& LANDAU, J. D. (1998). An investigation of everyday prospective memory. Memory \& Cognition, 26, 633-643.

MARTIN, M., \& EWERT, O. (1997). Attention and planning in older adults. International Journal of Behavioral Development, 20, 577-594.

Martin, M., \& Schumann-Hengsteler, R. (1996). Prospective memory in old age: An overview, practical suggestions, and future directions. Eichstätter Berichte zur Entwicklungs- und Paedagogischen Psychologie (No. 6). Eichstaett, Germany: University Press.

MAYLOR, E. A. (1996). Age-related impairment in an event-based prospective memory task. Psychology \& Aging, 11, 74-78.

MCDANiEl, M. A. (1995). Prospective memory: Progress and processes. 
In D. Medin (Ed.), The psychology of learning and motivation (Vol. 33, pp. 191-221). San Diego: Academic Press.

MCDaniel, M. A., \& Einstein, G. O. (1993). The importance of cue familiarity and cue distinctiveness in prospective memory. Memory, 1, 23-41.

McDaniel, M. A., Einstein, G. O., Manzi, M., \& Cochran, B. (1998). Strategic and automatic processes in prospective memory: $A$ multiprocess framework. Unpublished manuscript, University of New Mexico, Department of Psychology.

McDaniel, M. A., Robinson-Riegler, B., \& Einstein, G. O. (1998). Prospective remembering: Perceptually driven or conceptually driven processes? Memory \& Cognition, 26, 121-134.

Park, D. C., Hertzog, C., Kidder, D. P., Morell, R. W., \& Mayhorn, C. B. (1997). Effect of age on event-based and time-based prospective memory. Psychology \& Aging, 12, 314-327.

SALThouse, T. A. (1991). Mediation of adult age differences in cognition by reductions in working memory and speed of processing. Psy chological Science, 2, 179-183.

SALThouSE, T. A. (1994). Aging associations: Influence of speed on adult age differences in associative learning. Journal of Experimental Psychology: Learning, Memory, \& Cognition, 20, 1486-1503.

Salthouse, T. A., \& Meinz, E. J. (1995). Aging, inhibition, working memory, and speed. Journal of Gerontology: Psychological Sciences 50B, P297-P306.

Shallice, T., \& Burgess, P. W. (1991). Deficits in strategy application following frontal lobe damage in man. Brain, 114, 727-741.

Smith, A. D., \& EARLES, J. L. K. (1996). Memory changes in normal aging. In F. Blanchard-Fields \& T. M. Hess (Eds.), Perspectives on cognitive change in adulthood and aging (pp. 192-220). New York: McGraw-Hill.

Somerville, S. C., Wellmann, H. M., \& Cultice, J. C. (1983). Young children's deliberate reminding. Journal of Genetic Psychology, 143, 87-96.

Spieler, D. H.. Balota, D. A.. \& Faust, M. E. (1996). Stroop performance in healthy younger and older adults and in individuals with dementia of the Alzheimer's type. Journal of Experimental Psychology: Human Perception \& Performance, 22, 461-479.

STROOP, J. R. (1935). Studies of interference in serial verbal reactions. Journal of Experimental Psychology, 18, 643-662.

WATERS, G. S., \& CAPLAN, D. (1996). The measurement of verbal working memory capacity and its relation to reading comprehension. Quarterly Journal of Experimental Psychology, 49A, 51-79.

WeCHSLER, D. (1981). WAIS-R manual. New York: The Psychological Corporation.

WEST, R. L. (1988). Prospective memory and aging. In M. M. Gruneberg, P. E. Morris, \& R. N. Sykes (Eds.), Practical aspects of memory: Current research and issues. Vol. 2: Clinical and educational implications (pp. 119-125). Chichester, U.K.: Wiley.

Wilson, B. A., Cockburn, J., \& Baddeley, A. D. (1985). The Rivermead Behavioral Memory Test. Titchfield, U.K.: Thames Valley Test Co.
ZACKS, R. T., \& HASHER, L. (1994). Directed ignoring: Inhibitory regulation of working memory. In D. Dagenbach \& T. H. Carr (Eds.), Inhibitory processes in attention, memory, and language (pp. 24l-264). San Diego: Academic Press.

\section{NOTE}

1. We thank Judi Ellis for these observations.

\section{APPENDIX \\ Scoring Protocol for Plan Elaboration}

Subject No. 7

Recorded plan: "My plan is to start with 'Finding of the actual word' - with A - and then I'm going to jump down to the pictures. I'm starting with the first one, because I'll be better at it. And then I'm going to jump down to 'Naming pictures', because it sounds like fun - I'll do A - and then, I guess, I'll do the 'Arithmetic problems'- A - even though I don't like them very much and then I'll just go in the same order of one, three, two on the B part; so they are not too close together and I'm following the rules."

Scoring:

(1) Number of rules: 1

“... so they are not too close together and I'm following the rules"

(2) Number of order specifications/reasons for the order: 3

"I'm starting with the first one, because I'll be better at it."

"And then I'm going to jump down to 'Naming pictures', because it sounds like fun"

"and then, I guess, I'll do the 'Arithmetic problems' even though I don't like them very much"

(3) Number of executable items: 12 (2 points for each item)

Finding of the actual word - Version A

Naming pictures - Version A

Arithmetic problems - Version A

Finding of the actual word - Version $B$

Naming pictures - Version $B$

Arithmetic problems - Version B

Plan complexity score: $1+3+12=16$

(Manuscript received November 16, 1998; revision accepted for publication October 10, 1999.) 